\title{
Alternativas tecnológicas para planejamento urbano e energético sustentável: uma comparação entre Brasil e Alemanha
}

\author{
Technology alternate for sustainable urban and energy planning: a comparison between Brazil \\ and Germany
}

\author{
Richard Lins Nogueira ${ }^{1}$ \\ Rebeca Alves Botelho ${ }^{2}$ \\ Carolina Laurindo Basso 3 \\ Saulo Ribeiro dos $\operatorname{Santos}^{4}$ \\ Andréa Carolina Zapp ${ }^{2}$
}

\begin{abstract}
Resumo
$\mathrm{Na}$ atualidade, a sustentabilidade se apresenta como grande norteadora das políticas públicas nos mais diversos países do mundo. A presente pesquisa busca discutir os princípios do planejamento urbano e tecnologias de produção energética sustentáveis no Brasil, comparando-os com a situação na Alemanha. Mediante método exploratório e descritivo, possibilitado por pesquisa bibliográfica e documental, o projeto destina-se conclusivamente à análise integrada dos resultados e eventual comparação. Para a análise, conforme a metodologia, trabalhou-se numa análise FOFA (Forças, Oportunidades, Fraquezas e Ameaças) do cenário brasileiro, principalmente o energético. Também foi feita uma análise comparativa entre o Brasil e a Alemanha no que se refere ao sistema nacional de geração de energia elétrica. Assim sendo, concluiu-se que mesmo que o Brasil não tenha adotado a sustentabilidade como princípio base para suas diretrizes governamentais, diferente da Alemanha, o panorama entre os países se mantém equilibrado, não havendo grandes disparidades entre as duas realidades. Porém, há de se acentuar que o cenário brasileiro se estabelece devido à casualidade advinda de sua condicionante hidrológica e natural, que possui um imenso potencial para implementação de energias realmente limpas, e não de um planejamento sustentável conciso.
\end{abstract}

Palavras-chave: Sustentabilidade. Tecnologia. Energias renováveis. Brasil. Alemanha.

\begin{abstract}
Today, sustainability is presented as the great guiding public policy in various countries of the world. This research aims to discuss the principles of urban planning and sustainable energy production technologies in Brazil, comparing them with the situation in Germany. Through exploratory and descriptive method, made possible by literature and documents, the project is intended conclusively to the integrated analysis of the results and comparison purposes. For analysis, on methodology, worked on a SWOT analysis (Strengths, Weaknesses, Opportunities and

\footnotetext{
${ }^{1}$ Mestrando em Arquitetura e Urbanismo pelo PPGAU/UFF. E-mail: richardlinsnog@ hotmail.com.

2 Arquiteta Urbanista (PUC/PR).

${ }^{3}$ Graduanda em Arquitetura e Urbanismo (PUC/PR).

${ }^{4}$ Doutor em Gestão Urbana (Pontifícia Universidade Católica do Paraná). Doutorando em Geografia (UFPR).
} 
Threats) of the Brazilian scene. A comparative analysis between Brazil and Germany with regard to the national power generation system was also made. Therefore, it is concluded that even if Brazil has not adopted sustainability as a principle basis for their government guidelines, unlike Germany, the outlook across countries remains balanced, with no major differences between the two realities. But there is to stress that the Brazilian scenario is established due to accident arising from their hydrologic and natural condition, which possess immense potential for the implementation of truly clean energy, not a concise sustainable planning.

Keywords: Sustainability. Technology. Renewable energies. Brazil. Germany.

\section{Introdução}

Na elaboração da Agenda 21 (1995), a humanidade se viu em um momento de definição histórica, no qual o agravamento da fome, da pobreza, do analfabetismo e a deterioração contínua dos ecossistemas expôs a necessidade imediata de tomar o desenvolvimento sustentável como meio de gestão do planeta (SACHS, 1993).

Dentro desse contexto, as cidades assumem uma importante função devido ao crescimento expressivo do número de habitantes e à consequente degradação da qualidade de vida das pessoas (CREPALDI, 2003), apresentando assim uma necessidade de implementação de estratégias que promovam os conceitos de sustentabilidade e qualidade de vida urbana em seus diversos níveis de abrangência.

Com base nesses preceitos, a presente pesquisa visa inventariar modelos de referência empírica e de soluções tecnológicas em sustentabilidade no planejamento urbano e produção energética no Brasil.

\section{Sustentabilidade}

O termo sustentabilidade foi delineado na Conferência das Nações Unidas sobre o Meio Ambiente Humano, realizada em 1972, referindo-se a uma forma de desenvolvimento na qual as necessidades do presente são atendidas sem comprometer a possibilidade de as gerações futuras atenderem as suas necessidades (COMISSÃO MUNDIAL SOBRE MEIO AMBIENTE E DESENVOLVIMENTO, 1991). 
Em 1992, a ECO-92, realizada no Rio de Janeiro, consolidou o conceito de desenvolvimento sustentável, sendo saudado como o mais importante e promissor encontro planetário do final do século XX, culminando na publicação da Agenda 21 (NAÇÕES UNIDAS, 1995), um documento que busca identificar os problemas prioritários, os recursos, os meios para enfrentá-los e as metas para as próximas décadas.

Sachs (1993, p. 37-38) divide a sustentabilidade em cinco dimensões:

a) "Sustentabilidade social", entendida como maior equidade na distribuição do "ter" e da renda de modo a melhorar a qualidade de vida das massas.

b) "Sustentabilidade econômica", possibilitada a partir de maior eficiência na gestão econômica dos recursos públicos e privados.

c) "Sustentabilidade ecológica", promovida a partir de um manejo mais racional dos recursos potenciais dos vários ecossistemas, abrangendo desde novas soluções tecnológicas, institucionais, legais até limitações de consumo.

d) "Sustentabilidade espacial", voltada a uma distribuição mais equilibrada dos assentamentos urbanos e um melhor equilíbrio entre a configuração rural-urbana.

e) "Sustentabilidade cultural", promovida através da inserção do conceito de ecodesenvolvimento no seio da continuidade cultural de forma a respeitar as especificidades de cada ecossistema e cultura.

A partir de debates realizados em todo o país, foi desenvolvida a Agenda 21 brasileira (COMISSÃO DE POLÍTICAS DE DESENVOLVIMENTO, 2004), definindo desafios emergenciais a serem enfrentados, bem como propostas para sua resolução. Nesse documento foram definidas linhas estratégicas de sustentabilidade, voltadas à transformação da realidade brasileira, a qual foi também dividida em 5 dimensões:

a) Dimensão geoambiental: uso sustentável, conservação e proteção dos recursos naturais; ordenamento territorial urbano e regional sustentáveis; manejo adequado dos resíduos, efluentes, das substâncias tóxicas e resíduos radioativos; e manejo sustentável da biotecnologia.

b) Dimensão social: medidas de redução das desigualdades e de combate à pobreza; proteção e promoção das condições de saúde humana e seguridade social; promoção da educação e cultura para a sustentabilidade; proteção e promoção dos grupos estratégicos da sociedade (principalmente aqueles em situação de vulnerabilidade social). 
c) Dimensão econômica: transformação produtiva e mudança dos padrões de consumo; inserção econômica competitiva; geração de emprego e renda; reforma agrária e urbana; dinâmica demográfica; e sustentabilidade.

d) Dimensão política e institucional: integração entre desenvolvimento e meio ambiente na tomada de decisões; descentralização para o desenvolvimento sustentável; democratização das decisões e fortalecimento do papel dos parceiros do desenvolvimento sustentável; cooperação, coordenação e fortalecimento da ação institucional; instrumentos de regulação.

e) Dimensão da informação e do conhecimento: desenvolvimento tecnológico e cooperação; difusão e transferência de tecnologia; geração, absorção, adaptação e inovação de conhecimento; informação para a tomada de decisão; promoção da capacitação; e conscientização para a sustentabilidade.

O conceito de sustentabilidade demonstra ser abrangente e transversal, assente num conjunto de princípios de base e diretamente relacionado com a implementação de boas práticas de gestão. Para a presente pesquisa, se dará enfoque às concepções citadas, analisando os casos de planejamento urbano e de produção energética sob uma égide que busque transcender o tecnicismo, avaliando seus aspectos sociais, econômicos, ecológicos, espaciais e culturais, e no caso brasileiro, a observação da implementação das estratégias constantes na Agenda 21 nacional.

\section{Planejamento urbano sustentável}

Os processos de urbanização ao redor de todo o mundo têm exercido uma grande pressão sobre o solo edificado, a água e as energias disponíveis, mostrando grandes sinais de tensão como o crescimento desordenado, barreiras no espaço físico das cidades, diversas formas de poluição, densificação e expansão urbana (GARCIAS, SOTTORIVA et al., 2010). Hoje, pouco mais da metade da população mundial vive nas cidades, consumindo três quartos de toda a energia produzida no planeta e segundo projeções futuras, dois terços da população mundial viverão em aglomerados urbanos até 2050 (UNFPA, 2011). Dentro desse contexto, a gestão urbana deve utilizar-se dos instrumentos adequados ao desenvolvimento urbano sustentável, tendo em vista a integração dos diversos aspectos - citados no item anterior - que abrangem o conceito, tornando, 
desse modo, o processo de formulação de políticas e do planejamento urbano sustentável mais abrangente em relação a todos os aspectos que a sustentabilidade representa.

Não se deve entender as cidades como uma barreira para o desenvolvimento sustentável. Segundo Rogers (2001), as cidades podem ser pensadas para absorver o aumento no crescimento urbano e ainda ser autossustentáveis, entendendo que "as próprias cidades devem ser vistas como sistemas ecológicos e essa atitude traduz nosso pensamento no planejamento das cidades e no gerenciamento de seus recursos" (ROGERS, 2001, p. 30). Dessa maneira, devemos abandonar, segundo o autor, o "metabolismo linear" de consumo de recursos e passar a um "metabolismo circular", ${ }^{2}$, que permita a reutilização e maximização da eficácia no uso dos recursos no ambiente urbano. Vários autores apontam diferentes vieses estratégicos para o planejamento que vise ao desenvolvimento sustentável do meio urbano, como o já citado "metabolismo circular", e a disposição das densidades e equipamentos urbanos de maneira a maximizar seu uso e reduzir as distâncias a percorrer no ambiente urbano.

A proximidade entre os habitantes pode ser entendida como um ponto positivo para a sustentabilidade urbana, uma vez que essa configuração maximiza a eficiência dos investimentos em redes de abastecimento dos serviços essenciais (água, energia, esgoto e telecomunicações) (CREPALDI, 2003). Esse mesmo conceito é enfocado por Rogers (2001), apresentado como o modelo de "cidade densa" ou "cidade compacta", onde, segundo o autor, há maior eficiência energética, menor consumo de recursos (deslocamento), além de maior integração social, uma vez que as distribuições dos usos da cidade encontram-se sobrepostos e permitem maior integração, possibilitando aos cidadãos percorrer as distâncias a pé. Não se especula aqui, como nos modelos utópicos do século XX das cidades jardim, sobre o tamanho da cidade, mas sim sobre de qual maneira a distribuição de seus usos pode facilitar a vida de seus cidadãos e possibilitar uma menor dependência deles sobre veículos para realizar seus deslocamentos. Ou seja, a cidade - entendida como a extensão do território urbanizado - pode ter variados tamanhos, sendo importante a materialização de vários núcleos urbanos que possuam uso misto, densidades eficazes e sejam interconectados por transportes de massa. Dessa maneira, segundo o autor, os diversos núcleos

\footnotetext{
5 Por "metabolismo linear", compreende-se o processo em que as matérias-primas, alimentos e mercadorias, num geral, entram no ambiente urbano e, após utilizadas, são descartadas em forma de lixo, emissões e resíduos orgânicos poluentes. Por "metabolismo circular", compreende-se o processo em que após adentrar na cidade, as matérias-primas, alimentos e mercadorias são utilizados e continuamente reaproveitados de maneira não linear, no caso, de forma circular, reduzindo a produção de lixo, poluentes e, consequentemente, demandando menos recursos (ROGERS, 2001).
} 
atuariam como bairros autossustentáveis - no quesito de usos urbanos - que conectados gerariam a rede urbana, porém eliminando em muito as necessidades internúcleos.

Edwards (2008) apresenta três vértices do projeto sustentável: o social, o ambiental e o tecnológico. O autor explica que a abordagem atual da busca pelo desenvolvimento sustentável abandonou a posição estritamente focada nas questões ambientais, avançando para uma visão mais ampla das condições das cidades, representando agora um novo paradigma também para a equidade social, abrangendo dessa maneira as questões voltadas ao direito à cidade, às habitações populares e transporte de massa que possibilitem melhor qualidade de vida a seus cidadãos.

Estratégias de planejamento voltadas ao desenvolvimento sustentável devem balizar as forças políticas e comerciais voltadas ao declínio ambiental e desgaste da vida urbana, buscando equidade social e ambiental, explorando todos os meios possíveis, transformando nossas cidades destrutivas e alienadas em comunidades participativas e sustentáveis (ROGERS, 2001). Como exemplo o autor nos traz as diversas políticas executadas pelo governo Jaime Lerner em Curitiba, que além de buscar a construção de um ambiente urbano mais sustentável através de "um sistema de zoneamento em que os edifícios mais altos, residenciais e de escritórios alinham-se em torno dos cinco principais eixos de transporte de massa" (ROGERS, 2001, p. 61), foi também executado um amplo processo de conscientização ambiental em seus cidadãos, através de diversos cursos.

\section{Matriz energética sustentável no Brasil}

Tanto o Relatório de Brundtland da ONU (1991) quanto a Agenda 21 (1995) citam de maneira massiva o investimento em pesquisa, criação e implantação de tecnologias alternativas e ambientalmente saudáveis como um passo importante para o desenvolvimento sustentável. Dessa maneira, a sustentabilidade vem ocupando um lugar de destaque na vanguarda da ciência como base para tecnologias inovadoras (EDWARDS, 2008).

As tecnologias de caráter ambiental são divididas em duas categorias, segundo Andrade (2010):

a) Tecnologias de controle de poluição ou end-of-pipe: não alteram o sistema produtivo como tal, mas introduzem sistemas tecnológicos adicionais que capturam as emissões de poluentes a fim de diminuir o seu impacto sobre o ambiente. 
b) Tecnologias limpas: não buscam tratar a poluição após a sua emissão, mas tentam evitar ou reduzir tais emissões antecipadamente; focam as causas da degradação ambiental e não os efeitos.

Segundo Andrade e Silva Jr. (2010), dentre as tecnologias sustentáveis, as voltadas para a produção de energias renováveis possuem especial importância, uma vez que a matriz energética adotada mundialmente está baseada fortemente em energias não renováveis como o petróleo e o carvão, considerados os principais responsáveis pelo aquecimento. Dessa maneira, a presente pesquisa será direcionada às tecnologias sustentáveis dessa tipologia. A figura 1 apresenta a situação brasileira e confirma as preocupações de Andrade e Silva Jr. (2010).

No panorama brasileiro, a energia ofertada está próxima de um equilíbrio entre energias renováveis e não renováveis, com 59\% a 41\%, enquanto no mundo a proporção fica em 79,7\% para as não renováveis e 20,3\% para as renováveis (MINISTÉRIO DE MINAS E ENERGIA, 2015). Porém, é importante observar que entre as energias renováveis ofertadas no Brasil, a maioria ainda são tecnologias end-of-pipe, ou seja, não são realmente limpas, pois necessitam de sistemas adicionais que minimizem o seu impacto, como é o caso da matriz hidrelétrica brasileira, que geram grande impacto ambiental no espaço físico envolvido (SOUZA, RAMOS et al., 2003).

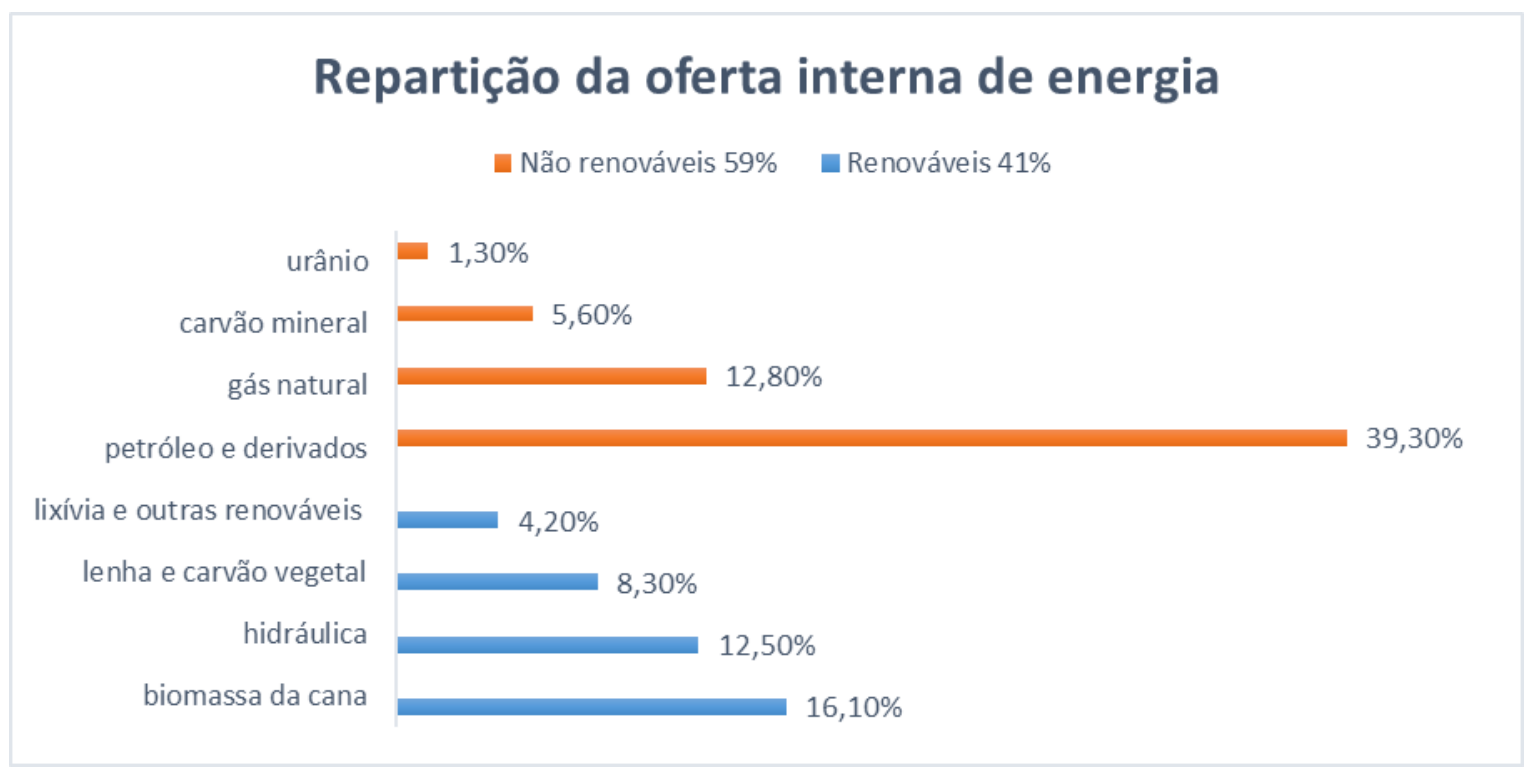

FIGURA 1 - REPARTIÇÃO DE OFERTA INTERNA DE ENERGIA NO BRASIL.

FONTE: Elaboração própria com base em dados do Ministério de Minas e Energia, 2015. 
As energias baseadas em tecnologias limpas, como a eólica e solar, ainda têm pouca representatividade na produção da energia brasileira, com apenas 1,1\%, mas com um crescimento de 16,5\% na capacidade instalada no último ano (MINISTÉRIO DE MINAS E ENERGIA, 2015).

Não há conhecimento de políticas públicas voltadas à ampliação da energia limpa ofertada ou incentivo a parcerias público-privadas. Dentre as maiores dificuldades de implantação dessas tecnologias no Brasil, as mais citadas são: a) os custos e riscos associados aos investimentos (89\%); b) a matriz energética atualmente dominante no país $(78,5 \%)$, visto que adquirir eletricidade não hidrelétrica ainda não é uma prioridade para o governo brasileiro; c) os riscos associados à inovação (62\%) (ANDRADE, SILVA JR. et al., 2010). Nesse aspecto, também é preocupante o crescimento da exportação do petróleo produzido no Brasil, direcionando as políticas públicas a essa matriz energética.

Porém, é extensa a bibliografia que explora a viabilidade da implementação de tecnologias limpas na produção energética nas mais variadas regiões do país. Dutra (2013) explora o potencial para a geração de energia eólica e solar fotovoltaica para pequenas propriedades rurais das Regiões Missões e noroeste do Rio Grande do Sul; Andrade (2010) apresenta a contribuição dos 37 projetos brasileiros, implantados nas mais diversas regiões, para o MDL (Mecanismo de Desenvolvimento Limpo) do protocolo de Kyoto; Arboit (2013) atenta para o grande potencial geotérmico inexplorado no Brasil; enquanto Braga (2012) explana sobre a riqueza do biodiesel brasileiro e a falta de políticas públicas que fortaleçam sua distribuição e produção.

\section{Matriz energética sustentável na Alemanha}

São grandes os investimentos da Alemanha em alternativas de captação de energias renováveis. Apesar de se tratarem de investimentos em longo prazo, estes vêm se mostrando eficientes já na atualidade, sendo possível notar uma diminuição relevante nas fontes de energias não renováveis e um aumento relativamente grande nas fontes de energias naturais, como é possível visualizar na Figura 2. 


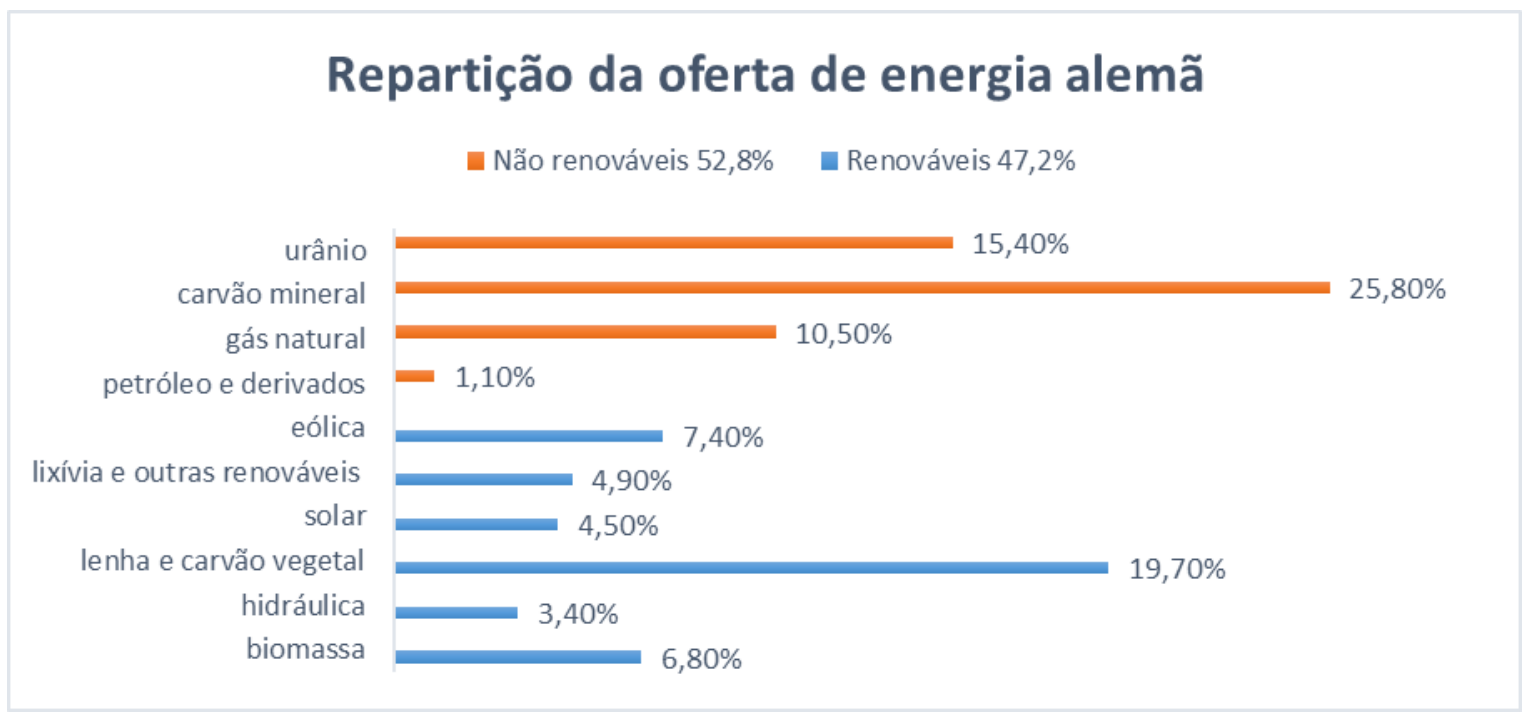

FIGURA 2 - REPARTIÇÃO DE OFERTA INTERNA DE ENERGIA NA ALEMANHA.

FONTE: Elaboração própria com base em dados do Statistisches Bundesamt (2014).

Segundo Orth (2014), já em 1991, a Alemanha buscava a emancipação de um arcabouço legal que ajudasse no estabelecimento de políticas sustentáveis. Nesse ano é vigorada a Lei do Aprovisionamento da Rede Pública, que compele as empresas fornecedoras de eletricidade a aproveitarem a energia de processos regenerativos de transformação, facilitando o aprovisionamento da "energia verde". Lei precursora da EEG (Lei das Energias Renováveis), de abril de 2000, que prioriza as fontes renováveis na ligação e alimentação da rede oferecendo condições para isso. Através da EEG, em 2012 as fontes renováveis já produziam 23,5\% de toda a eletricidade na Alemanha, o que resultou na economia de 146 toneladas de gases de efeito estufa. Hoje os pontos centrais da EEG são eficiência de custo e capacidade de planejamento.

Em dezembro de 2008, a União Europeia estabeleceu três metas básicas com o objetivo de construir um futuro sustentável para a Europa: reduzir em $20 \%$ as emissões de gases causadores do efeito estufa, aumentar a utilização das energias renováveis em $20 \%$ e reduzir o consumo de energia também a esse patamar. No entanto, o abastecimento energético sustentável já vem sendo um objetivo da Alemanha desde a década de 1970, quando o país passou a buscar uma revolução energética, energiewende, ou como chamado em português "virada energética", a qual é realmente fixada em 2013 (ORTH, 2014). A virada energética é atualmente o maior projeto sustentável em investimento na Alemanha (STATISTISCHES BUNDESAMT, 2014), visando total interrupção da produção de energia nuclear e, para isso, vem investindo em formas limpas de captação de energia como meta nacional. 
Segundo o Relatório Ambiental Alemão (SABIEL et al. 2010), o país é considerado um dos líderes na proteção do meio ambiente e sua parte no mercado mundial de tecnologias e serviços ambientais chega a 224 bilhões de euros. Em 2011, o ministro alemão de Meio Ambiente Norbert Röttgen anunciou que o ministério investiria, nos 184 novos projetos do setor de energia renovável, 128 milhões de euros no ano de 2011, sendo boa parte desses voltados a pesquisas na área de energia eólica e energia fotovoltaica. Em abril de 2011, o governo lançou o $6^{\circ}$ Programa de Pesquisa em Energia, com base no novo modelo energético do país. O objetivo é aumentar a eficiência e diminuir os custos da utilização de fontes renováveis e adequar a infraestrutura para a distribuição de energias. Por isso, pesquisas na área de tecnologias de armazenamento e redes de distribuição também são incentivadas. O ministro alemão ainda explica: "Para continuar fortalecendo as energias renováveis, a iniciativa privada e a comunidade científica devem investir em pesquisa e desenvolvimento. [...] O objetivo é tornar as empresas alemãs e os institutos de pesquisa mais competitivos no mercado internacional" (FREITAS, 2011).

Essas formas de captação de energias renováveis, que visam a um meio de produção limpo e que reduza a dependência de tecnologias end-of-pipe, vêm recebendo grandes incentivos do governo alemão e sobre elas desenvolvem-se inúmeras pesquisas e análises, tanto no que se refere à implantação como ao seu planejamento. A expansão desse tipo de tecnologia na Alemanha é o elemento central da transição do modelo energético atual para um sistema de energia contemporânea, sustentável e segura. Para ser implementado, foi estabelecida a Estratégia Nacional de Desenvolvimento Sustentável (2012) (em alemão, Nationale Nachhaltigkeitsstrategie), documento este que define, inclusive, as formas agressivas de incentivo governamental.

\section{Objetivos}

O objetivo geral da pesquisa consiste em comparar as experiências de planejamento urbano e tecnologias energéticas sustentáveis na Alemanha e no Brasil. Nesse contexto, os objetivos específicos da investigação pertinente ao presente plano de trabalho são:

a) Levantar e sistematizar a estado atual do planejamento urbano e das tecnologias energéticas sustentáveis no Brasil e Alemanha.

b) Diagnosticar deficiências e potencialidades dos modelos levantados, inter-relacionando-as. 
O alcance desses objetivos específicos deve responder ao questionamento sobre o real estado da inovação no planejamento urbano e tecnologias energéticas sustentáveis no Brasil e na Alemanha.

\section{Materiais e método}

Na primeira fase - estabelecimento de referencial teórico-conceitual e metodológico sobre o tema -, buscou-se comprovar as hipóteses anteriormente expostas, adotando-se uma estrutura investigativa de multimétodos (GIL, 2002), obtendo referenciais e dados científicos. A partir da exploração e levantamento de bases teórico-bibliográficas, de diversos autores, legislações e revisões de artigos científicos atuais, designou-se os temas tratados (planejamento urbano sustentável; sustentabilidade no Brasil e na Alemanha; tecnologias sustentáveis no Brasil e na Alemanha; e planejamento energético sustentável). Primeiramente, obtiveram-se as significações nominais e na sequência o aprofundamento dos conceitos, de forma que a primeira parte do estudo deteve-se a fundamentar o tema principal em uma visão ampla.

$\mathrm{Na}$ segunda fase buscou-se um modelo específico de análise, uma cidade com maior representatividade como estudo de caso para alternativas tecnologias para planejamento urbano sustentável no Brasil. Para isso, optou-se pelo SISU - Sistema de Índices de Sustentabilidade Urbana (BRAGA, 2006), o qual se baseia no Environmental Sustainability Index, proposto e desenvolvido pelas Universidades de Columbia e Yale para 142 países. O desenvolvimento de Índices de Sustentabilidade Urbana ainda é novo, havendo poucos autores que o sistematizaram de maneira abrangente, optando-se pelas recomendações de Braga (2006) devido à qualidade de sua revisão e formulação metodológica.

Segundo Braga (2006) a construção do sistema de índices deparou-se com o problema de tornar comparáveis dados de diferentes fontes, produzidos em escalas distintas, com cobertura espacial e distribuição temporal diversas, tornando difícil a sua compatibilização. Portanto, a elaboração desses índices e indicadores certamente está sujeito ao aperfeiçoamento inerente ao debate acadêmico. Dessa forma, o método aqui aplicado consta com várias alterações propostas por diversos autores, como Braga (2006), UNCHS (2010), UNFPA (2011) e IBGE (2010). 
O SISU é composto por três índices temáticos: índice ambiental (IA), índice de capacidade político-institucional (ICPI) e índice de desenvolvimento humano municipal (IDHM), os quais são conformados por diversos indicadores, como apresentados na Tabela 01.

TABELA 01 - SISU

\begin{tabular}{|l|l|}
\hline Índice & Indicadores \\
\hline IA & Saneamento básico \\
\hline \multirow{3}{*}{ IDHM } & IDH \\
\cline { 2 - 2 } & Veículos por habitante \\
\cline { 2 - 2 } & Densidade demográfica \\
\hline ICPI & Representatividade Política \\
\hline
\end{tabular}

Variáveis consideradas no cálculo do SISU

FONTE: elaboração própria com base em dados de Braga (2006), UNCHS (2010), UNFPA (2011) e IBGE (2010).

Os resultados obtidos a partir desses critérios estão apresentados no item seguinte.

Nessa fase também foi realizada a análise FOFA (Forças, Oportunidades, Fraquezas e Ameaças), de modo a diagnosticar o panorama brasileiro.

A última fase foi caracterizada pela consolidação dos resultados alcançados, sendo, a partir de técnicas dialéticas, apresentadas bases para o planejamento sustentável no Brasil. Essa fase permite a consolidação de conclusões e recomendações do estudo.

\section{Resultados}

\section{Modelo de referência em planejamento urbano sustentável no Brasil}

A partir de uma estrutura investigativa de multimétodos (GIL, 2002), buscaram-se vários estudos científicos que apresentassem casos bem-sucedidos de indicativos urbanos de sustentabilidade no Brasil, sendo eles: Araçatuba (MINAKI e AMORIM, 2012), Bauru (SANTOS, BOTEON et al., 2006), Curitiba (ROGERS, 2001), Joinville (KARAN, 2008), Passo Fundo (ROSSETTO, ORTH e ROSSETTO, 2006) e São José dos Pinhais (REICH, 2009). Estes foram submetidos à análise segundo os critérios estabelecidos no item anterior, como apresentado na Tabela 02 . 
Conforme os resultados visualizados na Tabela 02, a cidade selecionada foi Curitiba, obtendo maior média - 0,517 - no SISU.

No Brasil, Curitiba é uma das cidades que mais se destaca pela qualidade no planejamento urbano de caráter sustentável (ROGERS, 2001). Com a implementação do plano diretor de 1966, Curitiba buscou alterar o padrão de crescimento radioconcêntrico para um linear. Dessa maneira, a cidade passou a se configurar a partir de eixos estruturais formados pelo sistema trinário: uma zona que prevê elevado adensamento e uso misto do solo (residencial e comercial), duas vias lentas de acesso às atividades lindeiras e uma canaleta central exclusiva para a circulação das linhas expressas de transporte de massas (BRT - Bus Rapid Transit, ônibus de superfície de alta velocidade e alta capacidade), construídas a um custo de 200 mil dólares por quilômetro, em vez dos 60 milhões de dólares de um sistema convencional de metrô (ROGERS, 2001). Essa configuração, além de permitir um reforço às altas densidades através de um transporte de massa, ajuda a cidade a economizar $25 \%$ da sua energia, ao mesmo tempo em que consegue reduzir as emissões de dióxido de carbono (ALCUILY e DAVIDSON, 1998). Outro grande destaque, especificamente na parte tecnológica, é a energia usada na frota de veículos de transporte público de Curitiba; além do uso do álcool hidratado e do biodiesel, a cidade inova no uso de ônibus híbridos movidos à eletricidade e a biodiesel, os quais reduzem a poluição em até $80 \%$.

TABELA 2 - APLICAÇÃO DO SISU

\begin{tabular}{|c|c|c|c|c|}
\hline Cidade & Índice & Indicade & & Valor \\
\hline \multirow{5}{*}{ Araçatuba - SP } & IA & Saneamento básico & 0,881 & \multirow{5}{*}{0,3264} \\
\hline & \multirow{3}{*}{ IDHM } & IDH & 0,788 & \\
\hline & & Veículos por habitante & $-0,737$ & \\
\hline & & Densidade demográfica & 0,03 & \\
\hline & ICPI & Representatividade política & 0,67 & \\
\hline \multirow{5}{*}{ Bauru - SP } & IA & Saneamento básico & 0,879 & \multirow{5}{*}{0,384} \\
\hline & \multirow{3}{*}{ IDHM } & IDH & 0,801 & \\
\hline & & Veículos por habitante & $-0,63$ & \\
\hline & & Densidade demográfica & 0,09 & \\
\hline & ICPI & Representatividade política & 0,78 & \\
\hline \multirow{5}{*}{ Curitiba - PR } & IA & Saneamento básico & 0,996 & \multirow{5}{*}{0,517} \\
\hline & & IDH & 0,823 & \\
\hline & IDHM & Veículos por habitante & $-0,741$ & \\
\hline & & Densidade demográfica & 0,71 & \\
\hline & ICPI & Representatividade política & 0,797 & \\
\hline \multirow{4}{*}{ Joinville - SC } & IA & Saneamento básico & 0,959 & \multirow{4}{*}{0,416} \\
\hline & \multirow{3}{*}{ IDHM } & IDH & 0,809 & \\
\hline & & Veículos por habitante & $-0,592$ & \\
\hline & & Densidade demográfica & 0,08 & \\
\hline
\end{tabular}




\begin{tabular}{|c|c|c|c|c|}
\hline & ICPI & Representatividade política & 0,824 & \\
\hline \multirow{5}{*}{ Passo Fundo - RS } & IA & Saneamento básico & 0,989 & \multirow{5}{*}{0,4186} \\
\hline & \multirow{3}{*}{ IDHM } & IDH & 0,776 & \\
\hline & & Veículos por habitante & $-0,537$ & \\
\hline & & Densidade demográfica & 0,04 & \\
\hline & ICPI & Representatividade política & 0,825 & \\
\hline \multirow{5}{*}{ São José dos Pinhais - PR } & IA & Saneamento básico & 0,814 & \multirow{5}{*}{0,3752} \\
\hline & \multirow{3}{*}{ IDHM } & IDH & 0,758 & \\
\hline & & Veículos por habitante & $-0,543$ & \\
\hline & & Densidade demográfica & 0,05 & \\
\hline & ICPI & Representatividade política & 0,797 & \\
\hline
\end{tabular}

Avaliação dos municípios segundo o SISU

FONTE: elaboração própria com base em dados de Braga (2006), UNCHS (2010), IBGE (IBGE, 2010) e UNFPA (2010).

\section{Diagnóstico do cenário brasileiro: uma comparação com o panorama alemão}

Assim como exposto no item anterior, para diagnosticar a cenário brasileiro quanto as energias renováveis, foi utilizada a análise FOFA, para posterior comparação com os dados sobre a Alemanha.

A Tabela 03 apresenta as Forças, Oportunidades, Fraquezas e Ameaças no cenário brasileiro. A Tabela 04 apresenta o cruzamento dos dados com o uso da análise FOFA.

\section{TABELA 3 - DADOS DA ANÁLISE FOFA}

\begin{tabular}{|l|l|}
\hline \multirow{2}{*}{ Forças } & Casos de planejamento urbano inovadores. \\
\cline { 2 - 2 } & Grande potencial para a produção de energia limpa. \\
\cline { 2 - 2 } Oportunidades & Matriz energética sustentável já equilibrada. \\
\cline { 2 - 2 } & $\begin{array}{l}\text { Dendência internacional para a adoção da sustentabilidade. } \\
\text { sustentável. }\end{array}$ \\
\hline \multirow{2}{*}{ Fraquezas } & Energias limpas com pouca representatividade. \\
\cline { 2 - 2 } & Estratégias ainda em fase inicial. \\
\hline \multirow{2}{*}{ Ameaças } & Descoberta do pré-sal. \\
\cline { 2 - 2 } & Crescente exportação do petróleo brasileiro. \\
\hline
\end{tabular}

Forças, oportunidades, fraquezas e ameaças: dados para cruzamento no método FOFA

FONTE: Elaboração própria com base nas informações constantes no item Sustentabilidade. 


\begin{tabular}{|c|c|c|}
\hline & Fraquezas & Forças \\
\hline Ameaças & $\begin{array}{l}\text { A fase inicial das estratégias voltadas para a área } \\
\text { justifica a baixa representatividade das energias } \\
\text { limpas no Brasil. Esse cenário tende a piorar com a } \\
\text { descoberta do pré-sal e a crescente exportação do } \\
\text { petróleo brasileiro. }\end{array}$ & $\begin{array}{l}\text { Apesar da grande produção e exportação de } \\
\text { petróleo, o cenário torna-se equilibrado quanto à } \\
\text { disposição de energias renováveis. Há também } \\
\text { que ressaltar os casos de sucesso e inovação no } \\
\text { planejamento urbano. }\end{array}$ \\
\hline Oportunidades & $\begin{array}{l}\text { A tendência para a adoção da sustentabilidade } \\
\text { como modelo de gestão em grande parte do mundo, } \\
\text { incentivados pela disseminação dos modelos } \\
\text { sustentáveis, podem ser um incentivo à execução } \\
\text { das estratégias traçadas na área, aumentando a } \\
\text { representatividade das energias limpas no cenário } \\
\text { brasileiro. }\end{array}$ & $\begin{array}{l}\text { O cenário é positivo quando se analisa o potencial } \\
\text { brasileiro para a produção de energias realmente } \\
\text { limpas, que se somando às energias renováveis já } \\
\text { implementadas, os casos de sucesso e inovação } \\
\text { de planejamento urbano e os inúmeros acordos } \\
\text { internacionais, tende a revolucionar o panorama } \\
\text { existente no país. }\end{array}$ \\
\hline
\end{tabular}

FONTE: Elaboração própria com base nas informações constantes na Tabela 03.

\section{Discussão}

A partir do referencial teórico, torna-se evidente como as tecnologias voltadas ao planejamento urbano e energético sustentáveis podem em muito contribuir para as políticas de gestão urbana, com meios de reduzir o consumo energético nas cidades, além de possibilitarem meios de produção de energia que reduzam em muito os poluentes e diminuam a necessidade do uso de tecnologias end-of-pipe.

Apesar de não ser totalmente usado, o quadro energético já implementado e o potencial brasileiro existente são em muito animadores. Uma comparação entre a oferta de energia no Brasil e na Alemanha (Figuras 3 e 4) mostra que o Brasil possui um equilíbrio na oferta de energias renováveis e não renováveis, próximo ao ofertado pela Alemanha. 


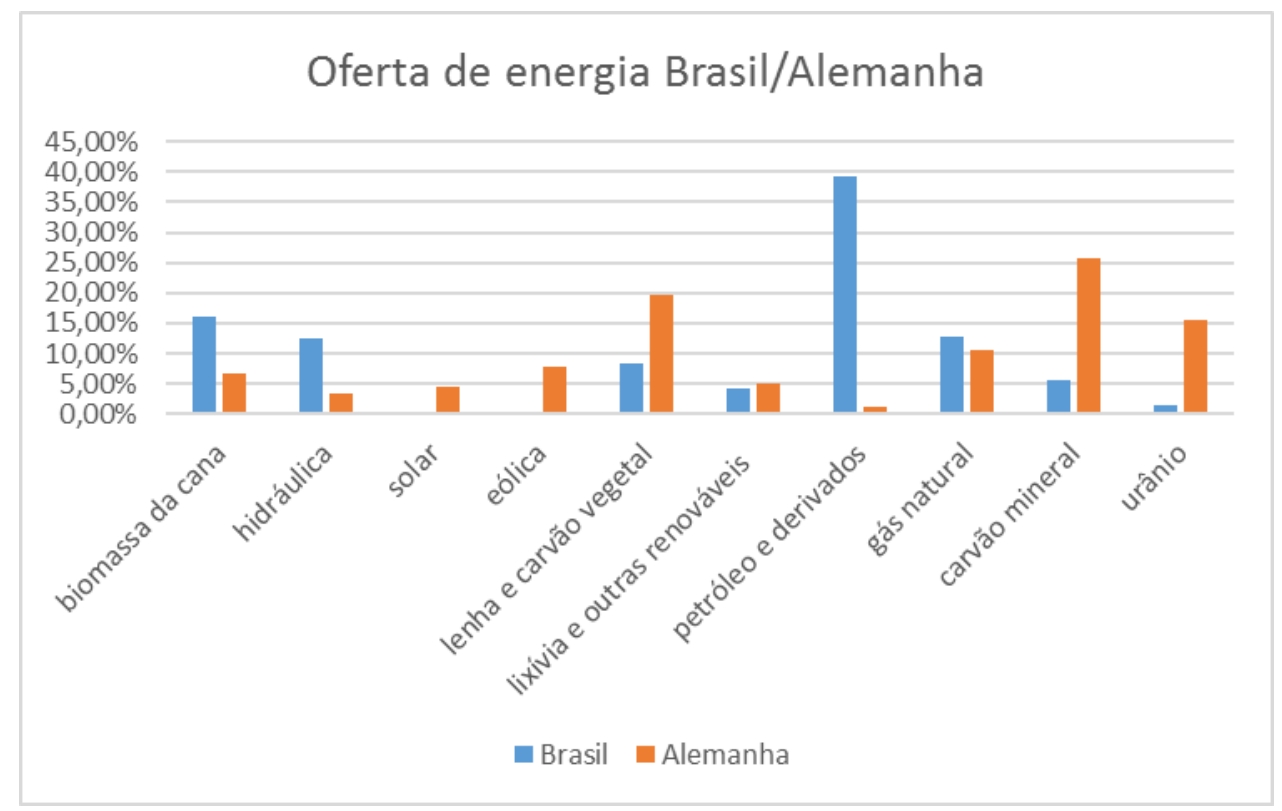

FIGURA 3 - COMPARAÇÃO DO QUADRO ENERGÉTICO OFERTADO PELO BRASIL E ALEMANHA

FONTE: Elaboração própria com base em dados do Ministério de Minas e Energia (2015) e Statistisches Bundesamt (2014).

Porém, é importante observar que as energias renováveis ofertadas pela Alemanha são em grande parte conformadas por energias limpas, como eólicas e fotovoltaicas, diferente do quadro brasileiro, que dispõe quase que totalmente da biomassa e hidráulica, energias renováveis, porém, não limpas.

Outro adendo que também merece atenção são as diversas políticas públicas alemãs voltadas para a produção de energias limpas, como a virada energética. Tal projeto visa total interrupção da produção de energia nuclear e, para isso, vem investindo em formas limpas de captação de energia como meta nacional. 


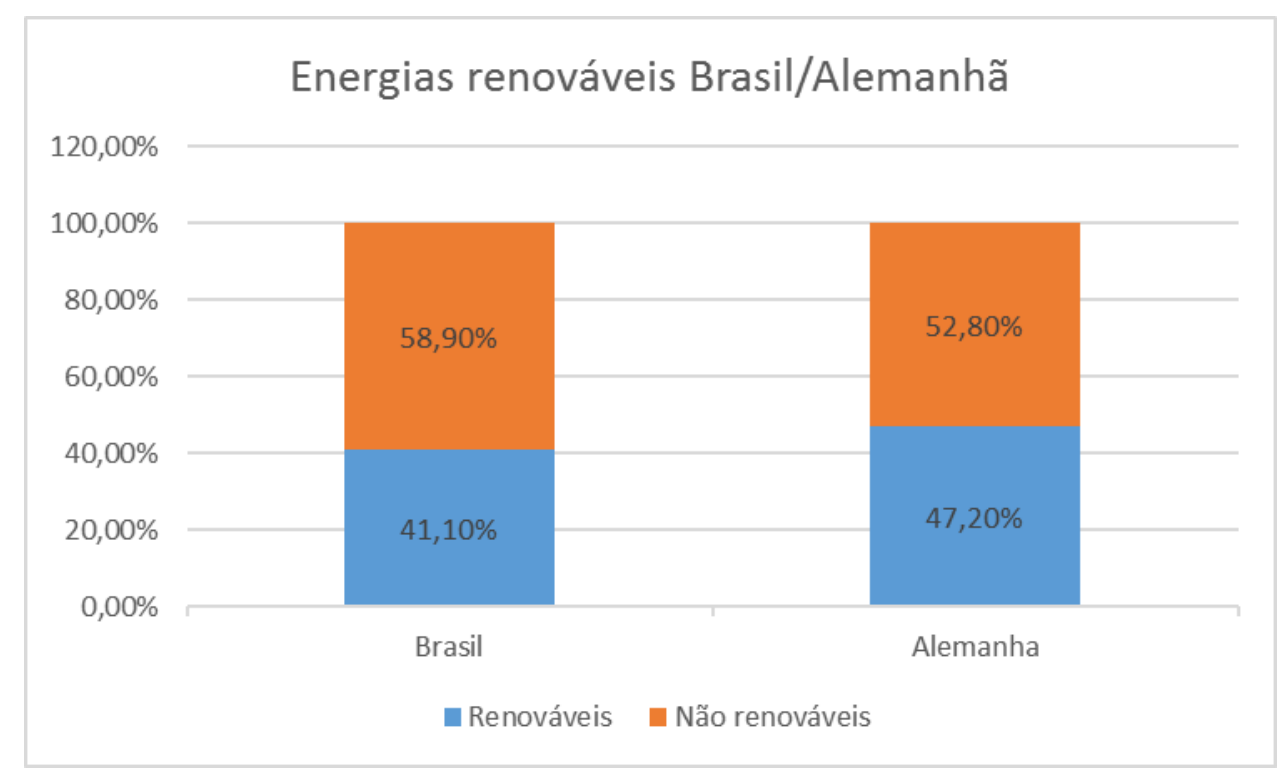

FIGURA 4 - COMPARAÇÃO DO EQUILÍBRIO ENTRE ENERGIAS RENOVÁVEIS E NÃO RENOVÁVEIS OFERTADAS PELO BRASIL E ALEMANHA.

FONTE: elaboração própria com base em dados do Ministério de Minas e Energia (2015) e Statistisches Bundesamt (2014).

Também é importante notar a diferença de foco nos estudos brasileiros e alemães para a área. Por mais que no Brasil a bibliografia sobre o assunto seja vasta, as pesquisas ainda estão em uma fase "bruta", buscando novos métodos de se utilizar da grande variedade de recursos locais de maneira a implementar e desenvolver tecnologias sustentáveis; enquanto na Alemanha, uma vez que a implementação já está acontecendo e as tecnologias alternativas já estão à disposição, as pesquisas são, em sua maior parte, voltadas para aprimoramentos de tecnologias já existentes (como maior eficiência em células fotovoltaicas).

\section{Conclusões}

Com o desenvolvimento de pesquisa bibliográfica e documental para a análise das condições de desenvolvimento sustentável no Brasil, constatou-se que há no país um enorme potencial para a adoção da sustentabilidade como meio de gestão, com a existência de projetos que visem ao desenvolvimento sustentável e a promulgação de diversas estratégias para a construção de um cenário mais sustentável no país. No entanto, na maioria dos casos essas propostas são ainda muito novas e, em grande parte, não foram aplicadas, ou seja, demonstra que ainda estamos em uma fase 
inicial, quase teórica, da transição para o desenvolvimento sustentável. O quadro energético existente é animador, mas não é fruto de uma gestão sustentável em específico, e sim consequência do rico potencial hidrológico e de agricultura do país.

$\mathrm{Na}$ Alemanha, por sua vez, ocorre quase o contrário. Mesmo com um cenário ambiental que, quando comparado ao Brasil, possui poucas alternativas, a produção de energias renováveis é em grande escala; é justamente através de altos investimentos em tecnologias e aplicação de metas de planejamento que vêm realmente sendo aplicadas que no seu quadro energético se demonstra um equilíbrio entre a produção de energias limpas e não limpas. Quadro que a julgar pelas diversas estratégias adotadas pelos governos atuais, tende melhor continuamente.

Dessa maneira, podemos constatar, a partir da comparação do cenário entre os dois países, que mesmo que o Brasil não tenha adotado a sustentabilidade como princípio base para suas diretrizes governamentais, diferente da Alemanha, o panorama entre os países se mantém equilibrado, não havendo grandes as disparidades entre as duas realidades. Enquanto na Alemanha sua situação é resultado de uma série de investimentos em tecnologias de produção de energias sustentáveis e da efetivação de planos diversos, no Brasil o cenário se apresenta como uma consequência de sua própria condicionante ambiental. Porém, a partir das inúmeras pesquisas voltadas para a implementação de energias renováveis, as inúmeras estratégias traçadas para o desenvolvimento sustentável, e a repercussão que o assunto "sustentabilidade" tem tomado no mundo, observamos um cenário positivo para o futuro brasileiro, principalmente devido ao enorme potencial de seus recursos naturais disponíveis para a produção de energias realmente limpas.

\section{Referências}

ALCUILY, C.; DAVIDSON, F. Densidade urbana: um instrumento de planejamento e gestão urbana. Rio de Janeiro: Mauad, 1998.

ANDRADE, J. C. S. et al. Contribuição dos projetos de MDL brasileiros da indústria de energia para a promoção de tecnologias limpas em prol do desenvolvimento sustentável. Contextus: Revista Contemporânea de Economia e Gestão. v. 08, n. 01, p. 07-20, jan./jun. 2010. Disponível em: <http://www.periodicos.ufc.br/index.php/contextus/article/view/631/612>. Acesso em: 25 ago. 2015.

ARBOIT, N. K. S. et al. Potencialidade de utilização da energia geotérmica no Brasil - Uma revisão de literatura. Revista do Departamento de Geografia. São Paulo, v. 26, p. 155-168, 2013. 
Disponível em: <http://www.revistas.usp.br/rdg/article/view/75194/78742>. Acesso em: 02 dez. 2015.

BRAGA, C. F. G. V.; BRAGA, L. V. Desafios da energia no Brasil: panorama regulatório da produção e comercialização do biodiesel. Cadernos EBAPE.BR. Rio de Janeiro, v. 10, n. 03, set. 2012. Disponível em: <http://dx.doi.org/10.1590/S1679-39512012000300016>. Acesso em: 16 nov. 2015.

BRAGA, T. M. Sustentabilidade e condições de vida em áreas urbanas: medidas e determinantes em duas regiões metropolitanas brasileiras. EURE. Santiago, v. 32, n. 96, p. 47-71, 2006.

COMISSÃO DE POLÍTICAS DE DESENVOLVIMENTO. Agenda 21 brasileira: resultado da consulta nacional. $2^{\mathrm{a}}$ ed. Brasília: Ministério do Meio Ambiente, 2004.

COMISSÃO MUNDIAL SOBRE MEIO AMBIENTE E DESENVOLVIMETO. Nosso futuro comum. Rio de Janeiro: FGV, 1991.

CREPALDI, P. V. Projeto urbano sustentável como referencial teórico-conceitual para critérios e diretrizes para análise de projetos e empreendimentos de impacto urbanístico. ENECS - Encontro Nacional Sobre Edificações e Comunidades Sustentáveis, 3., 2003, São Carlos. Anais... :São Carlos UFSCar, 2003.

DIE BUNDESREGIERUNG. Nationale Nachhaltigkeitsstrategie. Fortschrittsbericht: Herausgegeben von Presse-und Informationsamt der Bundesregierung, 2012. Disponível em: $<$ http://www.bundesregierung.de/Content/DE/_Anlagen/Nachhaltigkeit-wiederhergestellt/2012-0418-fortschrittsbericht-2012-reinzeichnung.pdf?_blob=publicationFile>. Acesso em: 02 nov. 2015.

DUTRA, J. C. D. N. et al. Uma análise do panorama das Regiões Missões e noroeste do estado do Rio Grande do Sul sob o prisma da energia eólica e solar fotovoltaica como fontes alternativas de energia. Revista Paranaense de Desenvolvimento. Curitiba, v. 34, n. 124, p. 225-243, jan./jun. 2013.

EDWARDS, B. O guia básico para a sustentabilidade. Barcelona: Editorial Gustavo Gili, 2008.

FREITAS, L. Governo amplia investimento em energias renováveis. BrasilAlemanha News, 2011. Disponível em: <http://www.brasilalemanhanews.com.br/sustentabilidade/governo-ampliainvestimento-em-energias-renovaveis/>. Acesso em: 18 abr. 2016.

GARCIAS, C. M. et al. A questão das águas urbanas e a Agenda 21 Local. Ambiência. Guarapuava, v. 06, n. 03, p. 531-546, set./dez 2010. Disponível em: <http://revistas.unicentro.br/index.php/ambiencia/article/view/1240/1153>. Acesso em: 16 nov. 2015.

GIL, A. C. Como elaborar projetos de pesquisa. $4^{\text {a }}$ ed. São Paulo: Atlas, 2002.

IBGE. Indicadores de desenvolvimento sustentável. Rio de Janeiro: Ministério do Planejamento, Orçamento e Gestão, 2010. 
KARAN, C. A. )lanejando uma cidade sustentável: o caso do planejamento estratégico de Joinville. Curitiba: Pontifícia Universidade Católica do Paraná, 2008. Dissertação de Mestrado.

MINAKI, C.; AMORIM, M. C. D. C. T. A qualidade ambiental urbana na legislação municipal: exemplo do plano diretor de Araçatuba - SP. RA'E GA. Curitiba, v. 25, p. 218-251, 2012. Disponível em: <www.geografia.ufpr.br/raega/>. Acesso em: 03 dez. 2015.

MINISTÉRIO DE MINAS E ENERGIA. Dados diversos sobre o quadro energético do Brasil. Ministério de Minas e Energia, 2015. Disponível em: <http://www.mme.gov.br/> Acesso em: 20 nov. 2015.

NAÇÕES UNIDAS. Conferência das Nações Unidas sobre o Meio Ambiente e Desenvolvimento: Agenda 21. Brasília: Câmara dos Deputados, Coordenação de Publicações, 1995.

ORTH, M. O caminho da virada energética. Deutschland.de, 2014. Disponível em: <https://www.deutschland.de/pt/topic/politica/alemanha-e-europa/o-caminho-da-viradaenergetica>. Acesso em: 18 abr. 2016.

REICH, F. P. A importância da gestão em saneamento no município de São José dos Pinhais: saúde, qualidade ambiental e qualidade de vida. 2009. 139 f. Dissertação de mestrado. Pontifícia Universidade Católica do Paraná, Curitiba, 2009.

ROGERS, R. Cidades para um pequeno planeta. Barcelona: Editorial Gustavo Gili, 2001.

ROSSETTO, A. M.; ORTH, D. M.; ROSSETTO, C. R. Gestão ambiental integrada ao desenvolvimento sustentável: um estudo de caso em Passo Fundo (RS). RAP. Rio de Janeiro, v. 40, n. 05, p. 809-840, set./out. 2006.

SABIEL, F.; MASKE, C. V.; MAYER-RIES, J.; LIEBING, A. Umweltbericht 2010. Berlin: Bundesministerium für Umwelt, Naturschutz und Reaktorsicherheit (BMU), 2014.

SACHS, I. Estratégias de transição para o século XXI: desenvolvimento e meio ambiente. São Paulo: Studio Nobel, 1993.

SANTOS, C. M. R. G. D. et al. Gestão de cidades: um processo de desenvolvimento participativo Caso Bauru +10. Revista Ciências em Extenção. v. 02, p. 57, 2006.

SOUZA, L. C. L. D. et al. Cidades sustentáveis: um desafio comum para Brasil e Portugal. Anais: III ENECS - Encontro Nacional Sobre Edificações e Comunidades Sustentáveis. São Carlos: UFSCar. 2003.

STATISTISCHES BUNDESAMT. Energy, 2014. Disponível em: <https://www.destatis.de/EN/FactsFigures/EconomicSectors/Energy>. Acesso em: 25 set. 2015.

UNCHS. Agenda Habitat. United Nations Centre for Human Settlements, 2010. Disponível em: <http://www.unchs.org>. Acesso em: 30 nov. 2015. 
UNFPA. Relatório sobre a situação da população mundial, 2011. Disponível em: <http://www.un.cv/files/PT-SWOP11-WEB.pdf>. Acesso em: 30 nov. 2015.

Artigo recebido em 27/01/2016. Aceito para publicação em 02/06/2016. 